\title{
New Research Advances in Obesity: Relevant to Neurologic Disorders
}

\section{Jin Jun Luo ${ }^{1 *}$ and Nae J. Dun ${ }^{2}$}

${ }^{1}$ Departments of Neurology and Pharmacology, Temple University School of Medicine, Philadelphia, PA 19140, USA

${ }^{2}$ Department of Pharmacology, Temple University School of Medicine, Philadelphia, PA 19140, USA

Obesity is a chronic medical condition. In the United States, over two-thirds of adults are overweight, and one in three Americans is obese [1]. Obesity may cause a plethora of medical conditions such as diabetes, hypertension, heart disease, depression, dementia, degenerative osteoarthritis, certain types of cancer [2], and other chronic illnesses. In clinical neurology practice, disorders related to or exacerbated by obesity include stroke [2], headache [3], and nerve damage such as carpal tunnel syndrome [4], meralgia paresthetica [5], idiopathic intracranial hypertension [6], and multiple sclerosis [7].

The two most common indexes in classifying obesity are: body mass index (BMI) and waist-to-hip ratio. BMI, a ratio of body weight in kilograms divided by height in meters squared, is widely used for estimating body fat for most adults between 19 to 70 years of age, and correlates well with total body fat content in adults, despite that it does not distinguish excess fat from muscle builders and pregnant women. An adult who has a BMI of 25-29.9 is considered overweight and over 30 obese. BMI of 35-40 is classified as severe obesity, 40-44.9 morbid obesity, and BMI greater than 45 is super obesity. Considering ethnic factors, some nations have redefined obesity as BMI greater than 25 in Japan [8] and greater than 28 in China [9].

The measurement of waist-to-hip ratio (in inches) takes into account not only how much fat a person has but also where the fat is deposited. It is obtained by measuring the waist at its narrowest point and the hips at the widest point. The pattern of body fat distribution differs in men and women. Women usually deposit fat in their hips and buttocks, displaying a "pear" shape, while men deposit fat in abdomen, making an "apple" appearance. Waist-to-hip ratios of greater than 0.8 in women and more than 1.0 in men are "apples". Apple-shaped individuals are more likely to suffer from medical problems related to obesity.

Obesity has an adverse effect on health, leading to reduced life expectancy. On average, obesity reduces life expectancy by six to seven years $[2,10]$, A BMI of 30-35 reduces life expectancy by two to four years, while severe obesity $(\mathrm{BMI}>40)$ reduces life expectancy by 10 years [11].

Obesity has been implicated in the development of several neurological disorders as a modifiable risk factor. It may directly and/ or indirectly cause or exacerbate cardiovascular diseases, including stroke [2]. Stroke accounts for roughly one out of every 18 deaths and is the third leading cause of death in the United States. Approximately 795,000 Americans experience a stroke every year, which approximates to one stroke every 40 seconds [12]. It is well known that obesity causes insulin resistance leading to development of type II diabetes mellitus (DM) [13]. It is estimated that approximately $8.3 \%$ of all ages of Americans are affected by DM [14] in which approximately half would suffer from neuropathy [15]. Certain types of neuropathies may be directly caused by obesity, such as carpal tunnel syndrome [4] and meralgia paresthetica [5].

Chronic pain syndromes, including headaches from idiopathic intracranial hypertension, or pseudotumor cerebri, are frequently seen in obese individuals. The severity and frequency of migraine was well correlated with the degree of obesity $[1,3,16]$. On the other hand, weight loss may help to diminish migraines in obese individuals, for example, bariatric surgery, which reduces body weight, significantly reduces the frequency of migraine headaches in obese $17,18 \mathrm{a}$ and $18 \mathrm{~b}$ cognitive functions $[19,20]$. Moreover, obesity may increase the risk of developing CNS demyelination, such as multiple sclerosis (MS), in young adults. Obesity at age $18(\mathrm{BMI}>30 \mathrm{~kg} / \mathrm{m} 2)$ is associated with a greater than twofold increased risk of MS $(p=0.001)$, implying that prevention of adolescent obesity may contribute to reduced MS risk [7].

Currently, an oversimplified concept relative to the development of obesity is that it is a combination of excessive food intake and inadequate physical activity [21]. It is generally agreed that obesity results from interplay between genetic and multi-environmental factors. Genetics affect hormones that may be involved in fat regulation. Obesity has a familial tendency. An individual is more likely to become obese if one or both parents are obese. Environmental factors including diet habits such as overeating, frequent, and psychological eating [22,23], sedentary life style $[24,25]$, diseases, and medications may accelerate the development of obesity. However, medical treatment for obesity is usually disappointing and short-lasting.

Over the last several decades progress made in obesity research has provided a wealth of information. Genetic approach provides a powerful tool in solving some of the puzzles. Polymorphisms in various genes controlling appetite and metabolism predisposed to obesity when sufficient food energy is present [26]. People with two copies of the FTO gene (fat mass and obesity associated gene) has been found to have greater risk of obesity compared to those without the risk allele [27]. Human leptin, a hormone comprising of 167 amino acids, is produced in fat cells and also in the placenta. It plays a key role in regulating energy intake and energy expenditure, including appetite and metabolism. The human leptin gene is located on chromosome 7 [28]. Leptin controls body weight by signaling the brain to eat less when body fat stores are too high. If an inadequate amount of leptin is produced or leptin cannot signal the brain to eat less, obesity occurs.

Since the discovery of leptin, ghrelin, insulin, orexin, PYY 3-36, neuropeptide $\mathrm{Y}$, adiponectin, and many other signaling molecules have been added to the list of neurohormones that are implicated in energy metabolism. Of those, ghrelin is of particular interest because leptin

*Corresponding author: Dr. J.J. Luo, Department of Neurology and Pharmacology, Temple University School of Medicine, 3401 North Broad Street, Suite C525, Philadelphia, PA 19140, USA, Tel: 1-215-707-3040; Fax: 1-215-7078235; E-mail: jluo@temple.edu

Received July 07, 2012; Accepted July 07, 2012; Published July 09, 2012

Citation: Luo JJ, Dun NJ (2012) New Research Advances in Obesity: Relevant to Neurologic Disorders. Brain Disord Ther 1:e103. doi:10.4172/2168-975X.1000e103

Copyright: (c) 2012 Luo JJ, et al. This is an open-access article distributed under the terms of the Creative Commons Attribution License, which permits unrestricted use, distribution, and reproduction in any medium, provided the original author and source are credited. 
and ghrelin are considered to be complementary in their influence on appetite.

Ghrelin is a 28 amino acid peptide of hunger-stimulating hormone. It is produced primarily in the fundus of the human stomach and epsilon cells of the pancreas [29]. Ghrelin levels increase before and decrease after meals [29]. Ghrelin counteracts the effect of leptin which mediates long-term appetitive controls. Although administration of leptin may be effective in a small subset of obese individuals who are leptin deficient, most obese individuals are leptin resistant and have been found to have high levels of leptin [30]. This resistance is thought to explain in part why administration of leptin has not been effective in suppressing appetite in most obese people [31].

A newly discovered myokine, or muscle synthesized hormone, named irisin (after the Greek goddess messenger Iris), may shed additional light on the nature of signaling molecules that are involved in the development and/or progression of obesity. Boström and colleagues demonstrated that over expression of transcriptional co-activator PPAR-c co-activator-1 a (PGC1-a) in mouse muscle, stimulates the expression of FNDC5, a membrane protein that is cleaved and secreted as irisin. It comprises 112 amino acids and acts on white adipose cells, where the fat is stored, to stimulate UCP1 expression and a broad program of brown-fat-like cells development in vitro and in vivo [32]. The brown fat cells are rich in mitochondria and capable of producing energy and heat. Importantly, release of irisin could be induced with exercise, which in turn causes an increase in energy expenditure and reduces body weight in mice with no changes in movement or food intake [32]. The findings of increased irisin level by either exogenous source such as injection or gene transfer observed in animals or endogenously produced by exercise observed in both animals and humans bear a possible therapeutic potential [32]. If proven to be effective in reducing obesity and improving glucose homeostasis in clinical trials, irisin could be used for human metabolic diseases such as obesity and DM, and its related neurological disorders. Viewed in this context, the potential impact of irisin on metabolic diseases and clinical neurology practice may be expected for years to come.

\section{Reference}

1. Bigal ME, Libermanv JN, Lipton RB (2006) Obesity and migraine: A population study. Neurology 66:545-550

2. Haslam DW, James WP (2005) Obesity. Lancet 366: 1197-1209.

3. Bigal ME, Lipton R B (2008) Obesity and chronic daily headache. Curr Pain Headache Rep 12: 56-61.

4. Sharifi-Mollayousefi A, Yazdchi-Marandi M, Ayramlou H, Heidari P, Salavat A, et al. (2008) Assessment of body mass index and hand anthropometric measurements as independent risk factors for carpal tunnel syndrome. Folia Morphol (Warsz) 67: 36-42.

5. Harney D, Patijn J (2007) Meralgia paresthetica: diagnosis and management strategies. Pain Med 8: 669-677.

6. Wall M (2008) Idiopathic intracranial hypertension (pseudotumor cerebri). Curr Neurol Neurosci Rep 8: 87-93.

7. Munger KL, Chitnis T, Ascherio A (2009) Body size and risk of MS in two cohorts of US women. Neurology 73: 1543-1550.

8. Kanazawa M, Yoshiike N, Osaka T, Numba Y, Zimmet P, et al. (2002) Criteria and classification of obesity in Japan and Asia-Oceania. Asia Pac J Clin Nutr 11: S732-S737.

9. Bei-Fan Z (2002) Predictive values of body mass index and waist circumference for risk factors of certain related diseases in Chinese adults: study on optimal cut-off points of body mass index and waist circumference in Chinese adults. Asia Pac J Clin Nutr 11: S685-S693.

10. Peeters A, Barendregt JJ, Willekens F, Mackenbach JP, Mamun A, et al. (2003)
Obesity in adulthood and its consequences for life expectancy: a life-table analysis. Ann Intern Med 138: 24-32.

11. Whitlock G, Lewington S, Sherliker P, Clarke R, Emberson J, et al. (2009) Body-mass index and cause-specific mortality in 900000 adults: collaborative analyses of 57 prospective studies. Lancet 373: 1083-1096.

12. Lloyd-Jones D, Adams RJ, Brown TM, Carnethon M, Dai S, et al. (2010) Heart disease and stroke statistics - 2010 update: a report from the American Heart Association. Circulation 121: e46-e215.

13. Tataranni PV (2002) Pathophysiology of obesity-induced insulin resistance and type 2 diabetes mellitus. Eur Rev Med Pharmacol Sci 6: 27-32.

14. U.S. Department of Health and Human Services, Centers for Disease Control and Prevention, 2011. National diabetes fact sheet: national estimates and general information on diabetes and prediabetes in the United States, 2011 Available at http://www.cdc.gov/diabetes/pubs/pdf/ndfs_2011.pdf. Accessed July 3, 2012.

15. Pop-Busui R, Lu J, Lopes N, Jones TL (2009) Prevalence of diabetic periphera neuropathy and relation to glycemic control therapies at baseline in the BAR 2D cohort. J Peripher Nerv Syst 14: 1-13.

16. Bigal ME, Tsang A, Loder E, Serrano D, Reed ML, et al. (2007) Body mass inex and episodic headaches: a population-based study. Arch Intern Med 167: 1964 1970.

17. Bond DS, Vithiananthan S, Nash JM, Thomas JG, Wing RR (2011) Improvement of migraine headaches in severely obese patients after bariatric surgery. Neurology 76: 1135-1138.

18a.Gunay Y, Jamal M, Capper A, Eid A, Heitshusen D, et al. (2012) Roux-en-Y Gastric Bypass Achieves Substantial Resolution of Migraine Headache in the Severely Obese: a 9-year analysis of 81 patients. Surg Obes Relat Dis.

18b.Novak V, Fuchs L, Lantsberg L, Kama S, Lahoud U, et al. Changes in headache frequency in premenopausal obese women with migraine after bariatric surgery: a case series. Cephalalgia 31: 1336-1342

19. Kanaya AM, Lindquist K, Harris TB, Launer L, Rosano C, et al. (2009) Total and regional adiposity and cognitive change in older adults. The Health, Aging and Body Composition (ABC) Study. Arch Neurol 66: 329-335.

20. Fitzpatrick AL, Kuller LH, Lopez OL, Diehr P, O'Meara ES, et al. (2009) Midlife and late-life obesity and the risk of dementia: cardiovascular health study. Arch Neurol 66: 336-342.

21. Lau DC, Douketis JD, Morrison KM, Hramiak IM, Sharma AM, et al. (2007) 2006 Canadian clinical practice guidelines on the management and prevention of obesity in adults and children [summary]. CMAJ 176: S1-13.

22. Bleich S, Cutler D, Murray C, Adams A (2008) Why is the developed world obese? Ann Rev Public Health 29: 273-295

23. Drewnowski A, Specter SE (2004) Poverty and obesity: the role of energy density and energy costs. Am J Clin Nutr 79: 6-16.

24. Nestle M, Jacobson MF (2000) Halting the obesity epidemic: a public health policy approach. Public Health Rep 115: 12-24.

25. James WP (2008) The fundamental drivers of the obesity epidemic. Obes Rev 9: 6-13.

26. Poirier P, Giles TD, Bray GA Hong Y, Stern JS et al. (2006) Obesity and cardiovascular disease: pathophysiology, evaluation, and effect of weight loss. Arterioscler Thromb Vasc Biol 26: 968-976.

27. Loos RJ, Bouchard C (2008) FTO: the first gene contributing to common forms of human obesity. Obes Rev 9: 246-250.

28. Green ED, Maffei M, Braden VV, Proenca R, DeSilva U, et al. (1995) The human obese $(\mathrm{OB})$ gene: RNA expression pattern and mapping on the physical, cytogenetic, and genetic maps of chromosome 7. Genome Res 5: 5-12.

29. Inui A, Asakawa A, Bowers CY, Mantovani G, Laviano A et al. (2004) Ghrelin appetite, and gastric motility: the emerging role of the stomach as an endocrine organ. FASEB J 18: 439-456.

30. Hamann A, Matthaei S (1996) Regulation of energy balances by leptin. Exp Clin Endocrinol Diabetes 104: 293-300.

31. Flier JS (2004) Obesity wars: Molecular progress confronts an expanding epidemic. Cell 116: 337-350.

32. Boström P, Wu J, Jedrychowski MP, Korde A, Ye L, et al. (2012) A PGC1dependent myokine that drives brown-fat-like development of white fat and thermogenesis. Nature 481: 463-468. 